\title{
Building Community Social Capital: The Potential and Promise of Information and Communications Technologies
}

\author{
Kenneth E. Pigg \\ University of Missouri < piggk@missouri.edu > \\ Laura Duffy Crank



\begin{abstract}
Increasing community social capital is widely viewed as one of the benefits of the deployment of information and communications technologies. A meta-analysis of the literature related to social capital and ICTs is completed. Using the five elements of social capital generally described in the research literature, the meta-analysis examines the empirical findings related to each of these five elements. The results indicate that much work remains to be done before it can be said with any validity that ICTs can, in fact, create community social capital.
\end{abstract}




\section{Introduction}

Rhetoric abounds regarding the central importance of social capital in considerations of community sustainability and action. Considerable rhetoric also exists regarding the potential of modern information and communications technology (ICT) to affect the development of social capital in positive ways. Other observers have questioned the notion of using ICT to build social capital (Loader, et al, 2000) and revitalize local communities (Dutton, 1999), but have yet to provide an empirical analysis of this capability. This paper examines the relationship between social capital and the pervasive nature of ICT in almost every aspect of social life, especially where community is the desired outcome or context. The fundamental question to be examined is implied in the title: can ICT successfully build social capital in communities?

This paper first addresses the notion of social capital to determine what consensus might exist about the various dimensions of social capital. Next the paper discusses the functional elements of information and communications technology with an attempt to relate the functionality of ICT (primarily those that are computer-based and tied to the Internet) with the nature of social capital formation. Then the paper illustrates the basic argument through a consideration of bonding and bridging forms of social capital and draws some conclusions about the efficacy of technology in building social capital.

One caveat is important here: this is not a technological determinist view of social processes and the influences of technology. As Gurak (2001) has noted about the Internet, “...technologies are invented by people and imbued with design choices that give these devices (software included) certain trajectories. ...The choices built into the Internet, and the choices we then make about how to use it, require a far more critical framework than we currently have." This paper views the relationship more in the context of theories of "social construction of technology" and argues from the standpoint that people can and will decide how to use this technology for their own purposes, provided that the features of the technology make it possible to do so. This paper draws on the perspectives of social informatics (Kling, 2000). We examine central elements related to ICT and social capital to determine where there may be sufficient justification apparent to warrant empirical research.

\section{Community in Cyberspace}

By way of introduction it is useful to contextualize the discussion that follows by emphasizing the importance of community as both a setting and an outcome of social action as constructed in cyberspace. We believe this meta-analysis has relevance to both communities of place and virtual communities. Much of the hubbub surrounding the Internet's capabilities has been focused on its use to create virtual communities, on-line communities where people meet, greet, discuss, share and often develop relationships that become face-to-face (Rheingold, 2000). Jones (1998) believes that, although high expectations are not always fulfilled with new technologies, expectations for social change and community remain. Castells (2001) views the Internet as creating new forms of social organization, identity and inequality, and power, and that in contrast to claims purporting the Internet is a cause of alienation from the real world or a renewed source of community or, social interaction on the Internet; rather it seems to be directly affecting everyday life. Too often the rush to "wire America" has left communities of place, both rural and urban, disconnected from the most rapidly growing form of communication ever known and drained intellectual and economic assets from disadvantaged places (Sclove and Scheuer, 1996). The "digital divide" is not just about disadvantage based on literacy or socio-economic status or race or gender; it is also about places left behind.

Networked computer and communications systems have become embedded in the lives of many in North America. Allowing public access to the Internet fostered a great number of inquiries into the widespread use and applications of the Internet. There has been a great deal of empirically grounded research about ICT and social change that could better inform questions about the impact upon societal changes (Kling 2000). The research articles are scattered in many research journals and books in many disciplines, making it difficult for both scientists and non-scientists to locate these studies. Social informatics is a term used to bring together all of these ideas in the different disciplines and to strengthen the dialogue between these different specialists (Kling 2000). Kling (2000) refers to social informatics as "the body of research that examines the design, use, and consequences of information and communication 
technologies in ways that take into account their interaction with institutional and cultural contexts” (pp. 217-218).

Community informatics represents an emerging subset of social informatics that addresses the same concerns as restricted to and represented by community-based institutional and cultural factors (Gurstein 2001; Loader, et al., 2000). Community informatics tends to concentrate on communities of place rather than communities of interest. This field is focusing attention on social capital as well as studies related to community development (Doheny-Farina, 1996; Kavanaugh and Patterson, 2001; Pigg, 2001), rural economic development (Pigg and Crank, 2003), health care, and education. Additional work in this field is addressing issues such as sustainability of technology development efforts, community networking, digital divide factors (Civille et al, 2001), design issues and effective use (Gurstein, 2004).

\section{Social Capital}

Social capital is often seen as a function of network qualities, norms of reciprocity and trust. Robert Putnam, in his often-cited study of the state of Italian democracy (1993), cites these three elements as comprising the basic dimensions of social capital in Italian society and has extended this analysis to American society. Putnam, in his empirical measurement of social capital, also focuses on aspects of civic participation in social and governance contexts. More recently, Onyx and Bullen (2000) state that social capital contains five main themes: networks, reciprocity, trust, shared norms, and social agency. In the analysis by Wall, et al (1998), it is determined that social capital is “...composed of social networks which can be activated” (p.304) suggesting that social capital is instrumental in social action. Similarly, Woolcock (2001) defines social capital as “...norms and networks that facilitate collective action” (p.13). More specifically, Flora (1998) argues that only certain qualities of social networks are related to social capital, namely diversity and extensiveness. The "network" focus is popular with ICT researchers due to the parallel nature of social networks and physical communication networks that make up the Internet or other communication technologies.

We also find important the notion of the network comprising a resource that can be mobilized for instrumental action. Coleman (1990) argues that social capital is a “...set of resources that inhere in family relations and community social organization...”(p.300). For Coleman, social capital is intangible and is composed of obligations and expectations, a set of norms and effective sanctions that can affect behavior and information channels. Castle (2002) also notes that social capital has been used to analyze rural areas' potential to achieve objectives, reinforcing the notion of social capital as an instrumental resource. What is not so clear is the precise nature of the "resources" that comprise social capital. Castle (2002) argues that, as a form of "capital," these resources must be both durable and useful. That is, social capital has the capacity to be used in production or consumption and it can be used in more than one time period.

Wall and associates (1998) point out that a third basis for social capital is found in "reciprocity transactions" following the exchange theorists like Simmel who had a utilitarian view of social interaction and argued that such transactions could affect social status as well as economic position. The notion of a norm of reciprocity being related to social capital is well documented as an important element that facilitates the way in which interactions are structured among community members.

Portes and Sensenbrenner (1993) discuss a fourth basis for social capital: "bounded solidarity,” as well as a fifth, "enforceable trust," from Weber's analysis of the characteristic differences between formal and substantive rationality. Solidarity is also the focus of structural analyses such as those of Young, Spencer and Flora (1968) or Zekeri, Wilkinson and Humphrey (1994), among others. Solidarity operates as a source of collective identity and a resource for action against threats from external sources. The binding factor may be common interest, ethnicity, history, religion or culture, or anything else unique to a social group.

Weber's analysis is well known and there are a number of recent works that attempt to determine the nature of trust with regard to its relationship to social capital. For example, Farrell and Knight (2003) define trust as ".... a set of expectations held by one party that another party or parties will behave in an appropriate manner with regard to a specific issue” (p.540). Harkening back to Weber's analysis, they 
argue that the existence of institutions in social settings can influence the trustworthiness of the actors in such a way as to create ongoing relationships of trust among those actors. They suggest a model of the relationship between institutions and trust which presumes that institutions affect trust between actors insofar as they: "(1) give actors an incentive to behave in a trustworthy (or, in some circumstances, untrustworthy) manner and/or (2) affect social beliefs about the trustworthiness or untrustworthiness of actors through their dissemination of information about the expected behavior of others" (Farrell and Knight, 2003, p.542).

This brief review establishes five dimensions or components for social capital from the literature. Rather than follow the advice of some authors to "select one" from the above list (Leonard and Onyx, 2003), we use all five components. Our implicit assumption is that it is quite possible that a concept as complex as social capital is, indeed, composed of several dimensions and these five appear reasonable and well documented. This assumption does not extend to the notion that these five components are unrelated. In fact, the literature suggests that they may be interrelated in very complex and mutually reinforcing ways. Operationally speaking, however, these five dimensions can be treated as conceptually valid. Subject to further empirical research on the relationships among these five, we will proceed as if they were distinct.

Based on this proposition we now argue that these five dimensions form a basis for examining the initial hypothesis or research question: Can ICT build social capital? By examining Figure 1, we provide a framework for completing our analysis of the factors related to this question, namely the elements and capabilities of ICT and their relationship to building social capital.

As shown in Figure 1, the analysis that follows indicates the connection to ICT is based both in the communication and the information elements of ICT. As the following discussion outlines, ICT include functions that support both communication in various forms as well as information storage, retrieval, analysis and sharing. Each of these elements can be operationalized in software in one or more forms with applications currently available in cyberspace. For example, electronic mail or VOIP (Voice over Internet Protocol) represent communication software applications that permit individuals and groups to "talk" back and forth, exchanging various sorts of information. Video-conferencing is another application that permits communication and information exchange. On the information side are applications such as knowledge management and archival software functions, or even simple directory and calendar construction software systems that permit information to be created, stored and shared among various kinds of users. We discuss this distinction and its implications below in more detail.

This separation of information from communication is not trivial. It is acknowledged that information is shared in various forms of communication. Face-to-face conversation is one form of communication that includes information that is not communicated verbally (Schuler, 1993). Further, as we think about the relationship between information and social capital, Briggs (2003) has noted that social capital is built upon "instrumental" and "expressive" information forms. Similarly, it can be argued that communication includes both cognitive and affective content and that the "text" itself is meaningless without considering both content and context (Raber and Budd, 2004). The challenge in the ICT environment is to formulate formats and content in ways that communicate both the affective and cognitive elements. Cognitive elements of communication can be construed as having an instrumental purpose while the affective elements are primarily expressive. Our distinction in this discussion is that, for our analysis, communication includes both affective and cognitive, while the information category includes only the cognitive. 
Figure 1. Analysis Framework

\begin{tabular}{|l|l|l|}
\hline \multirow{2}{*}{ Social Capital Components } & \multicolumn{2}{|c|}{ ICT Elements } \\
\cline { 2 - 3 } Networks & Information & Communication \\
\hline Resource(s) for action & & \\
\hline Reciprocity transactions & & \\
\hline Bounded solidarity & & \\
\hline Enforceable trust & & \\
\hline
\end{tabular}

\section{Information and Communication Technologies}

Altheide (1994) discusses how new devices that have created innovative forms of communication have also altered the rules of communication in social life: "Contemporary social life is increasingly conducted and evaluated on the basis of organizational and technological criteria that have contributed to the development of new communication formats which modify existing activities as well as help shape new activities” (p.666). Altheide seeks to understand how information technology contributes to the nature, organization, and consequences of activities (Couch 1984; Meyrowitz 1985; Altheide and Snow 1991). Altheide (1994) focuses less on the "messaging"

component and more upon the logic, formats, and principles of communication technologies. Formal bureaucratic organizations operated in the belief that information technologies could provide more rational or efficient communication in which information and communication "chase each other," (Altheide 1994: 666). The functions, techniques, and principles of information technology in the organization have spilled over into other aspects of modern society. Altheide argues that there is a gap between the potential for these devices and applications but, in reality, people may resist; and personal and legal harm (e.g., the use of medical information databases for credit and legal purposes) are not uncommon.

The "ecology of communication" is a concept that helps to understand how social activities are connected with information technology and to provide a perspective for restructuring how communication frameworks can enlighten social participation and the resulting implications for social order (Altheide, 1995). The three dimensions of the "ecology of communication" are: an information technology, a communication format, and a social activity (Altheide, 1994). Altheide (1994) refers to ecology instead of organization of communication for several reasons:

First, ecology implies relationships related through processes of interaction; second, ecology implies a spatial and relational basis for a subject; third, the relations are not haphazard or wholly arbitrary in which connections have emerged that are fundamental for the technology to exist and operate; and fourth, ecologies are developmental, contingent, and emergent (p. 667).

Ecology is referred to as an emergent discourse or framework. Within this framework, Altheide (1994) utilizes two important concepts: information technology and format to describe how the elements of communication provide a structure, logic, and competence for social action. Information technology (IT) refers to external devices and procedures that are used in assisting to create, organize, transmit, store and retrieve information. (Altheide 1994). The way that the technology operates brings another dimension to any activity and can often reshape activities since IT follows a logic that involves principles and assumptions that differentiate the technology from other means of storing and disseminating information. 
Format is "the selection, organization, and presentation of experience and information," that acts to shape the nature of the activity and is implicitly an instance of social change within itself (Altheide 1994: 668; Snow 1983). Formats or applications provide the basic meaning to an activity that will always outnumber the types of IT. Dutton (1999) provides a similar perspective in his analysis of the elements of ICT.

Altheide (1994) wants to make it clear that the IT-format-activity relationship is significant to social life; it is the format of ICT that structures social ties between persons and connects them to activities. He provides a model to illustrate the relevance of organizational IT and formats for societal activities in which IT formats and an organizational context creates an effective environment for problem solving which, in turn, creates a format and organizational solution in which societal context and activities pervade the entire process. Both globally and locally, there are illustrations of the new relationships between information technologies, formats, and social action. We have all heard and used the cliché, "It's a small world," and have listened as many have noted that "the world is getting smaller," as new information and communication technologies bring us "closer together." Altheide observes the use of multiple formats of information technology in the Persian Gulf War, as electronic communication directed weapons operations, targeted decisions, and even images of the war in "real time" were streamed to United States citizens back home on national and local news stations. Altheide (1994) notes that different formats, but the same information technology brought together both "doing it" and "reporting it." The introduction of the Internet into mainstream public usage has created different formats for information technology that enables a flow of communication that isn't passive, but is a two-way transaction such as: email, chatting, and the use of social software.

DiMaggio et al. (2001) purport that the Internet is different from earlier communication technologies, as it offers different modes of communication (broadcasting, individual searching, group discussion) and different kinds of content (text, audio, visual images) in a single medium. Castells (2001) believes that persons transform technology by modifying it and experimenting with it; and the Internet is a type of technology that is even more deeply embedded in social history since it is, " a technology of communication" (p.4). Since the Internet transforms the way that people communicate, society is greatly affected by the Internet, although since so many actions are taking place by means of the Internet, humans are transforming this virtual technology as well. Castells refers to this process of a two-way transformation as a socio-technical pattern (2001). Resnick (2001) refers to sociotechnical capital as a "productive combination of social relations and information and communication technology (pp. 2-3).

We wish to differentiate the functionality of ICT more carefully along the lines implied by the type of technology referenced. That is, we wish to differentiate between the information and communication functions. ICT communication is multi-faceted and interactive, including text, audio and video, as well it may be real-time (as in VOIP) or asynchronous or archival/historical, not to mention any combination thereof. This capacity may offer some real possibilities for building social capital and creating community.

The communication function refers to the acts of transmitting information of different types, e.g., ideas and feelings, from one person to another. One of the unique features of Internet based communications is the capability of "one-to-many" communication. So, ICT communication may also be one person to many other persons. This transfer of information via the Internet is not unique to the technology, except for its one-to-many feature (and even teleconferencing by phone has this feature today) and is generally considered to supplement face-to-face communication rather than replace it or substitute for it. For example, Wellman et al (2001) have determined that the use of email and other Internet-based forms of communication are generally between people with established relationships and serve to communicate the needs for support and sharing of information necessary for maintaining a relationship.

This relationship-building activity seems very important to our consideration of how ICT might function to increase social capital. These relationships are acknowledged to exist in networks of kin, friends, professional colleagues, and other community members. Müller (1999) and Rheingold (2000) indicate that most relationships that are created online are continued in physical space, thus creating new forms of offline and online involvements. Hampton and Wellman (1999), and Wellman et al. (2001) state that online interaction increases social capital as it supplements physical local relationships, and high Internet usage is associated with increased participation in organizations. Wellman (1996) states, 
"Computer-supported social networks sustain strong, intermediate, and weak ties that provide information and social support in both specialized and broadly based relationships... Computer-mediated communication accelerates the ways in which people operate at the centers of partial, personal communities, switching rapidly and frequently between groups of ties" (p.352). In the "Netville" project, Hampton and Wellman (2001) found that, in a wired community, many neighbors got to know each other better through the use of a local computer network. In a study in Blacksburg, Virginia, Kavanaugh and Patterson (2001) studied the correlation between Internet use and community involvement and attachment over a three-year period. They found that there is a significant relationship between community involvement and predisposition to use the Internet for social-capital-building activities. In 1996, Internet users who reported communication with formal and informal social groups were also involved in their community. In 1999, this same pattern appeared to strengthen as people who used the Internet for small group and informal communication reported higher community involvement, whereas interaction with formal groups offline decreased by1999.

Other software tools that are used in this networking component would include discussion lists, chat rooms, VOIP, and video-conferencing. Each software tool has different features that better support some aspects of networking than others. For example, discussion lists are a form of communication that is "oneto-many," while email can be either one-to-one or one-to-many. VOIP, by comparison, can be many-tomany at least for a small number of people (limited by software and bandwidth capacity). Use of such tools can build and maintain social networks (Haythornthwaite and Wellman, 1998).

The information function is complex because Internet based information transfer can take place using a variety of features of the network. The information transfer can be "active," in that people share information using various communication features of the Internet including email and video conferencing, or it can be passive, based on one person's searching for resources on the Internet and using, for example, its archiving or knowledge management capabilities. Information can be transmitted in many forms. Most observers would not view the act of passively seeking and acquiring information from an archive as "communication", since this action generally is considered to require a two-way transaction involving "broadcast-reception-response-reception." The most visible example of the Internet's information-based capabilities is represented in the various on-line merchant catalogs for consumer sales (e.g., Amazon, Ebay, Yahoo, etc.). All these business models make use of a database storage system, a transaction system, a search system, and so forth, all of which we would classify as part of the information function of ICT as the communication involved is qualitatively different than, for example, in a personal email exchange.

It is not difficult to imagine a community-based system that would be primarily an information function as described above that would support the networking component of social capital building. Following Kretzman and McKnight's (1993) "asset model" of community building, the development of a searchable database that contains a brief description of community members' interests and skills (assets) could be useful in creating new networks among community members based on those interests or on skill building.

In addition, a similar kind of database could easily support the "resources for action" component of social capital. Knowing the assets of people in a network makes it very easy to determine who might be sufficiently interested in an issue or activity to become an active participant. The organization of on-line interest groups that share information about all sorts of topics as well as the self-organizing characteristics Rheingold (2002) describes as "smart mobs," the WTO protest groups or the Dean for President activists represent a mobilization of resources for action unlike any form of social organizing yet observed. These latter movements represent primarily the communication function, but knowing who shares your interest makes it that much easier to target communication activities.

The "reciprocity transaction" component of social capital is more complex. The action implied is straightforward enough: one person provides something of value to another in expectation that, at some point in time, the other person will act similarly. Such reciprocity may come upon request or not and may not occur for a long period of time after the initial transaction. Exchange research is full of such transactions and their social capital building effects in communities and groups. The expectation of reciprocity is usually unstated and informal rather than explicit and contractual. Different norms as to value 
and the eligibility of persons to participate in certain types of transactions are contextually specific. Usually, participation is limited to social network members rather than carried out with outsiders, but this is not always the case.

Putting aside commercial transactions in which cash is exchanged for materials goods and services, what kinds of valued things can be exchanged via ICT and is a reciprocity norm present and active? Insofar as communication may take place via the Internet that contains solicitations or offers for exchanges in which someone receives social support or valuable information not generally public, ICT can support the transaction element. The reciprocity element may be more difficult to verify or operationalize since the concept involves, primarily, informal or non-contractual relationships. For example, Miranda and Saunders (2003) have investigated reciprocity in the context of shared meanings created over the Internet when information is shared. They assert that "...intersubjective construction of meaning necessitates reciprocity" (p.89) and determine in their research that the lack of a "social presence" in electronic communications impedes reciprocity and interactivity. The "depth of information sharing did not produce shared meaning" without a form of shared presence, demonstrating again that communication involves more than words. Creating a "social presence" via the Internet is a capability that is, as yet, undocumented or, perhaps, untried.

Bounded solidarity is important in group and community identity. It has frequently been associated with social movements of resistance or opposition to power as this characteristic provides the sense of "being in this together" rather than facing threats or risks alone. Solidarity represents a social characteristic that makes it easy for outsiders to recognize members who share the characteristic. The boundary that sets a group or community apart may be ethnicity or social status or geography or history. This component of social capital solidifies connections between people who belong and makes it clear who does not.

For ICT, supporting the creation of bounded solidarity might be considered a difficult challenge. Certainly, our review of the related literature finds few documented examples of this being successfully established. In other settings it is clear that solidarity is established by communication among members of a group or community and ICT can certainly support this function. To the extent that people rally to a symbol, vision, or message communicated via ICT, those in charge of the organizing might contemplate using electronic mail, chat rooms, discussion lists and interactive web sites to publicize elements of the message to various audiences. Some messages could be directed at recruitment of people to the cause. Some messages could be targeted at individuals or groups to create stronger bonds among them based on the elements of solidarity being used or to create a sense of threat from external forces.

One can also imagine a database of, say, atrocities committed against the group for which the boundary is being emphasized as a way of supporting organizing efforts. The list of Jews who died in concentration camps is read each year on our university campus as a way of reminding Jews of one historical experience that separates them from other people as well as reminding non-Jews of the solidarity that Jews share as a social group. The Vietnam War Memorial represents a database of those who died in this conflict to which people can relate as friends and relatives and sympathizers. This "connection" binds visitors together who have never met each other by finding companionship and empathy with other visitors who share this experience. Transforming such experiences to the virtual space of the Internet is certainly within the realm of the technology. One example of how this might be done is a community site that emphasizes the unique history of the community in, say, the Civil War or the California Gold Rush, and the residents who shared that history through family members who were participants. Such "info sites" serve as good marketing tools in tourism promotion and may provide access to information about relatives, events, or other resources that attract visitors, especially those who may be doing some family genealogical work. Nevertheless, our research to date has not identified any examples of this sort of application.

What functional tools are available to achieve "enforceable trust"? There is a rapidly growing literature regarding the nature and role of trust, as well as the requirements for a trusting relationship, and the norms related to trusting behavior. This literature traces roots to Simmel (Möllering, 2001) as well as Weber (Farrell and Knight, 2003). Generally speaking, the evidence points to several dimensions of trust in human relationships. Trust is related to cognition and affective relationships (Möllering, 2001; McAllister, 1995). To the degree that we have "good reasons" to believe that someone will behave in a specific manner in a 
given situation, we extend trust to that person. Our "good reasons" may or may not be inherently rational, but each of us makes the choice as to what constitutes a reasonable basis and available knowledge. Such reasons might be competency, demonstrated willingness to take responsibility, reliability and dependability in similar situations or reputation as acknowledged by trusted affiliates (McAllister, 1995). Affective reasons for trusting someone might include a personal relationship with another person, altruism, the degree to which the other person expresses care or concern about one's situation, and the reciprocity shown or promised regarding one's situation (Rempel et al, 1985).

Another basis for trust can be found in institutional factors (Wall, et al, 1998; Farrell and Knight, 2003; Pavlou and Gefen, 2004). Such institutional-based trust is found in our dependence on professional norms and credentialing activities. Certain professions are licensed by the state and expected to perform according to related criteria. Ethics guide other professions as well as certifications. Pavlou and Gefen (2004) take this argument to another level in their review of online marketplaces. In their words, "this 'perceived effectiveness' captures the degree to which a buyer believes that institutional mechanisms provide recourse, are enforceable, are convenient, are available and are cost-effective, among other factors” (p. 38). They investigate four institution-based structures: feedback mechanisms, escrow services, credit card guarantees, and trust in the marketplace's intermediary. Their research shows that "trust in the community of sellers as a whole is a crucial factor in whether the buyer will consider purchasing products from any given seller" (p. 39). The use of ICT in this research is a direct concern and, even though the research by Pavlou and Gefen focuses on commercial activity, it is not hard to imagine that these kinds of institutional mechanisms might be replicated in non-commercial activities as well and thus produce social capital in other settings. For example, social service organizations might adopt such a model and provide parallel services to demonstrate to critical and risk-averse clients that the services they may receive from the organization are trustworthy and effective. Endorsements and referrals by related organizations more closely aligned with the social context of such clients (such as churches), affiliation with other trusted organizations such as food banks or homeless shelters, or other institutionally based demonstrations of the trustworthiness of the service provider could be demonstrated in internet based communication. Banking organizations working with the poor in third world situations that are owned by those served and governed by contemporaries in similar situations appear to be more trustworthy in the eyes of the poor than other financial institutions. Again, ICT - ignoring the lack of access possessed by such populations of poor people in third world nations - could easily be employed to handle financial transactions as trustworthy intermediaries. However, with the exception of many new E-government ventures, there do not appear to be many examples of such systems in operation, particularly serving geographically identifiable communities.

\section{Summary}

For this paper, the question becomes "does increased social capital derive from the communications or information functions of ICT or both?” We have cited examples of the use of the communication capacity to build and sustain social networks. Also cited are examples related to enforceable trust and resource mobilization. However, there are some gaps in the empirical knowledge that raise questions as to a positive answer to this research question. In Figure 2, the discussion in this section is summarized. With regard to the communication functions available via Internet technology it appears that three of the five components of social capital might be created. The relevance of the information functions of the Internet for achieving such an outcome is much more in question. It should be acknowledged that it is obvious our literature review is not yet complete as the relevant literature is quite fragmented and found in a wide variety of disciplinary sources as demonstrated in the references cited for this analysis.

It should also be noted that some research on other communication technology applications, e.g., video on demand, videotext, etc., as well as the Internet show that the user public is likely "...more interested in interpersonal and group communication and specialized services than in just having lots of information at their fingertips" (Dutton, 1999, p. 97). It is likely that content, per se, is not the driving force. Or, as some researchers describe it, the affective is clearly of higher priority than the cognitive in the applications valued by users of ICT. On the other hand, applications such as small video cameras that monitor children's daycare facilities for parents at home or work via computer/Internet connections can be an important valueadded functional use of ICT (Dutton, 1999, p. 100). 
Figure 2. Results of Review of Literature

\begin{tabular}{|c|c|c|}
\hline \multirow[b]{2}{*}{ Social Capital Components } & \multicolumn{2}{|c|}{ ICT Elements } \\
\hline & Information & Communication \\
\hline Networks & No empirical studies & Yes \\
\hline Resource(s) for action & No empirical studies & Yes \\
\hline Reciprocity transactions & No empirical studies & Yes \\
\hline Bounded solidarity & No empirical studies & No empirical studies \\
\hline Enforceable trust & $\begin{array}{l}\text { Yes, in commercial } \\
\text { applications and possibly E- } \\
\text { Government }\end{array}$ & No empirical studies \\
\hline
\end{tabular}

\section{Two Forms of Social Capital}

Leonard and Onyx (2002) examine how strong and loose connections of members of community organizations affect social capital. Bonding social capital is usually associated with strong ties of kin and neighborhood and localized trust (Leonard and Onyx 2002). In contrast, bridging capital is associated with Granovetter's notion of "weak ties" and "thin impersonal trust with strangers." Leonard and Onyx (2003) think that there are three uses of the concept of bridging capital in the discussion of social capital, in which the three uses are not necessarily meant to be used collectively:

To refer to relationships that cross demographic divides of class, age, ethnicity, etc. (e.g., Portes 1998); to refer to bridges across structural holes, or gaps between networks which are not necessarily of dissimilar people, but where there has hitherto been little connection-such gaps may occur for example as a result of geographic distance (e.g., Burt 1998); and to refer to the capacity to access resources such as finance, information, and knowledge from external sources to the organization or community (e.g., Woolcock and Narayan 2000) (p. 191).

Further, Leonard and Onyx (2003) believe that networks are lateral associations of individuals and groups, and that individuals working together create social capital, in which bridging social capital would involve a large, less dense network with fewer "multiplex" relationships. Reciprocity is referred to as the individual providing a service or favor in expectation that the favor will be returned. They believe that the conditions of reciprocity would need to be more clear and direct than those of bonding social capital. "Thick trust" is usually associated with bonding social capital whereas "thin trust" is associated with bridging social capital. Finally, social norms are an undocumented but commonly understood recipe for shaping what patterns of behavior are expected in a social context and what forms of behavior are valued or socially approved. Without strong norms, rules have to be negotiated, decided upon, and enforced for every interaction, making social relationships complex. Social norms are assumed with bonding social capital whereas bridging across social distances creates the need for the conscious exploration of norms and can only proceed if a foundation of shared values can be established (Onyx and Bullen 200, p.192).

The conceptualization of bridging and bonding capital above suggests that bridging social capital places agency as the central focus. Social connections are created mainly to increase agency, whereas the reverse is true for bonding social capital (Leonard and Onyx, 2003). Bridging social capital is associated with large, loose networks, relatively strict reciprocity, more frequent norm violation, a thinner or different 
sort of trust, and more instrumentality. Bonding social capital is associated with dense, multiplex networks, long term reciprocity, shared norms, thick trust, and less instrumentality.

The intersecting, close-knit ties of the well-bonded community can be harmful to bridging social capital or to extending relationships to a wider and more diverse group. Portes (1998) reviews the positive and negative effects of social capital, highlighting the possibility of negative effects of norms that enforce conformity and limit the ability for individuals and groups to move across social borders. Bonding social capital is composed of connections among persons and groups with similar backgrounds, such as similar ethnic groups or social characteristics, while bridging social capital links diverse community groups to each other and to groups external to the community (Flora and Flora, 2004). Bridging ties are usually purposive whereas bonding ties are emotionally charged (Briggs, 2003). Bridging capital encourages diverse ideas since it connects diverse people from a variety of cultural and social backgrounds.

Naranyan (1999) believes that bonding capital may actually be reinforcing social norms that encourage inequality and stratification, whereas bridging capital is developing cross-cutting or weak ties that facilitate access to information, resources, and opportunities. Leonard and Onyx (2003) studied how people understand and benefit from their strong and loose ties within the networks formed by community organizations in Australia. Study participants stated that their really strong ties were with their friends and family, but that their community organizations did provide opportunities for members to extend their networks. In rural settings, trust seemed to depend upon years of connection, whereas in urban areas, length of time is still important, but frequency and intensity of contact can be at least as important, particularly in new circles of people (Onyx and Bullen, 2003). Respondents also felt that reciprocity was an important aspect of strong ties in which many turned to their strong ties in times of need for material and emotional support. The sharing of common values and backgrounds was an essential ingredient for the development of strong ties. Many respondents believed that many of their loose ties involved people in the same networks as the strong ties, but a further relationship had not developed since history and common activities had not been shared or it was not possible to give the same intensity of emotional investment to everyone. Loose ties were often among members of the same organization who possessed different personal and social characteristics who gave a broader sense of perspectives to many respondents. The loose ties within organizations seemed to be bridging people across social categories. Leonard and Onyx (2003) believe that both strong and loose ties are found in organizational networks and their functions overlap such that both create a sense of belonging to achieve concrete outcomes for the community.

Leonard and Onyx (2003) found empirical evidence that links between groups were used to access information and other resources and were used to achieve outcomes that could not be accomplished solely from the resources of a single organization. Action and social agency was created by strong links across different groups and organizations within the same community. Briggs (2003) also notes the instrumental functions of bridging forms of social capital. Leonard and Onyx (2003) believe that the degree of trust plays an important role in determining whether people will take risks in bridging other networks to attain information or other resources. The looser links were characterized by lower degrees of trust, which were marked by differences in values in which trust was "thinner" and it is less likely that the loose ties would be used for helpful purposes.

Each community member has varied needs for bonding capital and intentionally works to acquire this based on emotional and (personal) material needs. Bonding capital is frequently derived from kinship networks and kinship norms that underlie both reciprocity and trust. "We trust each other because we are family." The norm is fundamental to the relationship and is most often affective and institutional. Bridging capital is, primarily, a basis for collective action and community members seek bridging capital to satisfy political and (collective) material needs; bridging capital requires mobilizing diverse assets and access to information about the who and the what. Bridging capital built upon a foundation of diversity in network quality, reciprocity based on exchanges of material and political assets, and trust based on long-term relationships in which behaviors has become reasonably predictable. Trust is based on cognitive and institutional factors.

Modifications to Figure 2 can be made to add the dimensions of these two forms of social capital. Adding another axis to represent these two forms would likely reinforce the conclusion already drawn: ICT 
can be useful in building social capital, but the empirical data have not documented this relationship as yet. ICT are more likely to be useful in increasing bonding capital via communication functions and bridging capital via information functions. Increases in bonding capital are likely derived from affective and institutional trust and reciprocity and solidarity. The networks of strong ties supporting bonding capital are taken for granted. Bridging social capital is derived from cognitive and institutional trust, reciprocity and resource mobilization as primary factors along with access to and support from diverse social networks of weak ties. This is not to suggest that increasing one form comes at the expense of the other form of social capital but does suggest that different technology applications and attributes will be effective in producing desired outcomes. Nevertheless, until there is evidence of more focused attention being directed to the dimensions of social capital and the two forms in which it is manifested-bonding and bridging-with regard to their information and communication aspects, we are unlikely to see much progress in the community venture of linking ICT to social capital development.

\section{Conclusions}

This meta-analysis of the relationship between social capital and information and communication technology is only a beginning but still suggests that a degree of "analytical skepticism" should be extended to the assertions of those advocating the deployment of ICT for creating social capital (Wolgar, 1999). Based on a deconstruction of the social capital concept, our analysis suggests ICT has the capability to contribute to enhancing and extending social networks, providing access to resources that can be mobilized for action, enhancing solidarity in social groups, and supporting mechanisms of enforceable trust and reciprocity in transactions. Our analysis distinguished between communication and information, as being of a different nature and function, especially as perceived by users. The empirical evidence to support the relationships described is yet very limited in many of these areas even if the potential may exist.

At the same time, it is entirely possible that the trajectory of development of these technologies is still in a very early stage and these applications are in the wings waiting for the appropriate "demand." From a community informatics perspective, however, waiting means taking the risk that the global influences so pervasive in cyberspace will never provide opportunity for "local" networks and content to gain a significant foothold. It is only when user-centered design and human-centered networks are given priority that opportunities for the creation of social capital and building stronger communities will be realized (Gill, 1996).

This analysis also focused primarily on communities of place rather than virtual communities. There may be cause for greater distinction in this analysis as some observers argue that geographically based communities are not well served by ICT (Beale, 2000). Many are not well connected with quality hardware systems and they often represent very complex technical situations. Regarding the potential of ICT, a strong argument can be made for the positive outcomes that might be experienced in building stronger communities and increasing social capital. ICT, it can be argued, can support collaboration and decentralized decision making among citizens. ICT can support learning functions that may reduce conflict and improve the quality of decisions and actions taken. As Beale (2000) states: "At a deeper level, communities need to be able to learn about themselves, their world and from their mistakes and successes" (p. 60). ICT can provide support for “...self-knowledge: of people, places, cultures and of resource usage; community memory and history via the knowledge of events over time; (and) the learning function: the ability to construct meaningful knowledge from data, facts and events." There would likely be little disagreement here, but this view is simply not (yet) supported by the evidence available and what evidence is present is focused almost entirely on communities of interest. Efforts to develop "local knowledge" for access via ICT must become much more focused on the specific forms of knowledge; its representations online, and the uses people have for this kind of knowledge. Access to local knowledge must also take into account a broader range of technological tools than is present in most community networking activities. Schuler's (1993) observation that most of what takes place online is "conversation," does not represent the full capacity of this technology. A more complete understanding of the differences between forms of communication and information storage and retrieval (in the context of ICT) must be fostered if successful creation of social capital is to be achieved. More research and further documentation is necessary before we can say for certain that ICT can and do create social capital and, thereby, build community. Enhancing social networks is obviously necessary, but this analysis suggests it is certainly not sufficient to support the 
claim of ICT advocates. However, the empirical records are so fragmented among disciplines and sources that this meta-analysis has only scratched the surface. Further, it had to rely on research into some factors that did not include reference to the role and functionality of ICT, forcing the authors to extrapolate from potential to possible. 


\section{References Cited}

Altheide, David L. (1994). “An Ecology of Communication”, The Sociological Quarterly, 35(4), pp.665683.

. (1995). An Ecology of Communication: Cultural Formats of Control. Hawthorne, NY: Aldine de Gruyter.

and Robert P. Snow. (1991). Media Worlds in the Postjournalism Era. Hawthorne, NY:

Aldine de Gruyter

Beale, Thomas. (2000). "Requirements for a Regional Information Infrastructure for Sustainable Communities-The Case for Community Informatics.” In M. Gurstein, (Ed.), Community Informatics: Enabling Communities with Information and Communications Technologies (pp. 5280). Hershey, PA: Idea Group Publishing.

Briggs, Xavier de Souza. (2003). “Types of Social Capital.” in K. Christensen and D. Levinson (eds.), The Encyclopedia of Community: From the Village to the Virtual World, (pp. 1277-1283). Thousand Oaks, CA: Sage Publications.

Burt, R. (1997). “The Contingent Value of Social Capital.” Administrative Science Quarterly, 42, pp.332365.

Castells, M. (2001). The Internet Galaxy : Reflections On The Internet, Business, And Society. New York: Oxford University Press.

Castle, E. (2002). “Social Capital: An Interdisciplinary Concept.” Rural Sociology, 67, pp. 331-349.

Civille, R., Gurstein, M. and Pigg, K. (2001). “Access to What? First Mile Issues for Rural Broadband” Report prepared for the Computer Science and Telecommunications Board, Broadband Last Mile Technology Project. National Research Council. Washington, D.C.

Coleman, J. S. (1990). Foundations of Social Theory. Cambridge, MA: The Belknap Press.

Couch, Carl. (1984). Constructing Civilizations. Greenwich, CT: JAI.

Dimaggio, P., Hargittai, E., Neuman, R., and Robinson, J. (2001). Annual Review of Sociology, 27, pp.307336.

Doheny-Farina, S. (1996). The Wired Community. New Haven, CT: Yale University Press.

Dutton, W. H. (1999). Society on the Line: Information Politics in the Digital Age. Cambridge: Oxford University Press.

Farrell, H \& Knight, J. (2003). “Trust, Institutions and Institutional Change.” Politics and Society, 32(3), pp.537-566.

Flora, C. and Flora, J. (2004). Rural Communities: Legacy and Change. Boulder: Westview Press.

Flora, Jan. (1998). “Social Capital and Communities of Place.” Rural Sociology 63(4), pp.481-506.

Gill, K. S. (1996). “Knowledge and the Post-Industrial Society.” in Karamjit S. Gill (ed.), Information Society: New Media, Ethics and Postmodernism, pp. 3-29. London: Springer.

Gurak, L. J. (2001). Cyberliteracy: Navigating the Internet with Awareness. New Haven, CT: Yale University Press.

Gurstein, M. (ed.). (2001). Community Informatics: Enabling Communities with Information and Communications Technologies, Hershey, PA: Idea Group Publishing.

. 2004. "Effective Use: A Community Informatics Strategy Beyond the Digital Divide." First Monday, December 2003. Accessed July 19, 2004 from http://www.firstmonday.dk/issues/issue8_12/gurstein/index.html. 
Hampton, K. and Wellman, B. (1999). "Netville Online and Offline: Observing and Surveying a Wired Suburb." American Behavioral Scientist 43 (3), pp.475-492.

Haythornthwaite, C. and Wellman, B. (1998). "Work, Friendship and Media use for Information Exchange in a Networked Organization.” Journal of the American Society for Information Science, 49(12), pp. 1101-1114.

Jones, S. (ed.). (1998). CyberSociety 2.0: Revisiting Computer-mediated Communication and Community. Thousand Oaks, CA: Sage Publications.

Kavanaugh, A.L. \& Patterson, S. (2001). “The Impact of Community Computer Networks on Social Capital and Community Involvement.” AmericanBehavioral Scientist, 45(3) pp. 496-509.

Kling, R. (2000). "Learning about Information Technologies and Social Change: The Contribution of Social Informatics.” The Information Society, 16, pp.217-232.

Kretzman, J.P., \& McKnight, J.L. (1993). Building Communities From The Inside Out. Evanston, IL: Center for Urban Affairs and Policy Research, Northwestern University.

Leonard, R and Onyx, J. (2003). "Networking Through Loose and Strong Ties: An Australian Qualitative Study.” International Journal of Voluntary and Nonprofit Organizations, 14(2), pp.189-203.

Loader, B. D., Hague, B. \& Eagle, D. (2000). “Embedding the Net: Community Empowerment in the Age of Information," in M. Gurstein (Ed.) Community Informatics: Enabling Communities with Information and Communications Technologies, pp. 81-103. Hershey, PA: Idea Group Publishing.

McAllister, D. J. (1995). “Affect- and Cognition-based Trust as Foundations for Interpersonal Cooperation in Organizations.” Academy of Management Journal, 38(1), pp. 24-59.

Meyrowitz, J. (1985). No Sense of Place. New York: Oxford Press.

Miranda, S. M. and Saunders, C. S. (2003). "The Social Construction of Meaning: An Alternative Perspective on Information Sharing.” Information Systems Research, 14(1), pp. 87-106.

Möllering, G. (2001). "The Nature of Trust: From Georg Simmel to a Theory of Expectation, Interpretation and Suspension.” Sociology, 35(2), pp.403-420.

Müller, C. (1999). “Networks of 'personal communities' and 'group communities' in different online communication services.” Proceedings of the Exploring Cyber Society: Social, Political, Economic and Cultural Issues, Vol II, July 5-7 1999. Newcastle, G.B.: University of Northumberland. Accessed July 20, 2004 from: http://www.soz.unibe.ch/ii/virt/newcastle.html.

Naranyan, D. (1999). "Bonds and Bridges: Social Capital and Poverty.” Policy Research Working Paper 2167. Poverty Division, Poverty Reduction, and Economic Management Network, The World Bank. Online. Accessed July 12, 2004 at: http://www.worldbank.org/poverty/scapital/library/narayan.pdf.

Onyx, J \& Bullen, P. (2000). “Measuring Social Capital in Five Communities.” Journal of Applied Behavioral Science, 36(1), pp.23-42.

Pavlou, P. A. and Gefen, D. (2004). "Building Effective Online Marketplaces with Institution-Based Trust.” Information Systems Research, 15(1), pp.37-59.

Pigg, K. (2001). "Applications for Community Informatics for Building Community and Enhancing Civic Society.” Information, Communication, \& Society 4(4), pp. 507-527.

\& Crank, L. D. (2003). “Community Social Infrastructure: Shaping the Successful Application of Information Communication Technologies for Rural Economic Development.” Paper presented at the $4^{\text {th }}$ Annual Conference on Information Technologies in Regional Areas, Brisbane, Australia, December.

Portes, A. 1998. "Social Capital: Its Origins and Applications in Modern Sociology.” Annual Review of Sociology. 24, pp.1-24. 
\& Sensenbrenner, J. (1993). "Embeddedness and Immigration: Notes on the Determinants of Economic Action.” American Journal of Sociology, 98: 1320-1350.

Putnam, R. (1993). Making Democracy Work: Civic Traditions in Modern Italy. Princeton, N.J: Princeton University Press.

Raber, D. and Budd, J. M. (2004). “Information as sign: semiotics and information science.” Journal of Documentation, 59(5), pp.507-522.

Rempel, J.K., Holmes, J.G., and Zanna, M.D. (1985). “Trust in Close Relationships.” Journal of Personality and Social Psychology, 49, pp.95-112.

Resnick, P. (2001). "Beyond Bowling Together: SocioTechnical Capital,” working paper. University of Michigan School of Information.

Rheingold, H. (2000). The Virtual Community: Homesteading on the Electronic Frontier, Revised Edition. Cambridge, MA: The Harvard University Press. . (2002). Smart Mobs: The Next Social Revolution. Cambridge, MA : Perseus Publishing.

Sclove, R. and Scheuer, J. (1996). "On the Road Again? If Information Highways are Anything Like Interstate Highways-Watch Out!” in Rob Kling (ed.), Computerization and Controversy: Value Conflicts and Social Choices, Second Edition, pp. 606-613. San Diego: Academic Press.

Schuler, D. (1993). New Community Networks: Wired for Change. New York: Addison-Wesley Press.

Snow, R. P. (1983). Creating Media Culture. Beverly Hills, CA: Sage

Wall, E, Ferazzi, G. \& Schryer, F. (1998). “Getting the Goods on Social Capital.” Rural Sociology, 63, pp.300-322.

Wellman, B. (1996). "Are Personal Communities Local? A Dumptarian Reconsideration" Social Networks, 18(3), pp.347-354.

, Hasse, A. Quan, Witte, J., \& Hampton, K. (2001). “Does the Internet Increase, Decrease or Supplement Social Capital: Social Networks, Participation, and Community Commitment.” American Behavioral Scientist, 45-3, November, pp. 436-455.

Woolgar, S. (1999). “Analytical Skepticism.” in William H. Dutton (Ed.), Society on Line: Information Politics in the Digital Age, pp. 335-337. Oxford: Oxford University Press.

Woolcock, M. and Deepa Naranyan. (2001). "Social Capital: Implications for development theory, research and policy,” World Bank Research Observer, 15(2), pp.225-249.

Young, F., Spencer, B.W., and Flora, J. (1968). "Differentiation and Solidarity in Agricultural Communities.” Human Organization, 27, pp.344-351.

Zekeri, A., Wilkinson, K.P. and Humphreys, C.R. (1994). "Past Activeness, Solidarity and Local Development Efforts.” Rural Sociology, 59, pp.216-235. 